\title{
STUDIES OF ELECTRICAL AND OPTICAL PROPERTIES OF Sn DOPED AND UNDOPED ZnO THIN FILMS BY THE SPRAY PYROLYSIS METHOD
}

\author{
A.ARATO ${ }^{1,2}$, S.M. GARCÍAMONTES ${ }^{1}$, G. ALAN CASTILLO ${ }^{1}$, T.K. DAS ROY ${ }^{1}$. \\ ${ }^{1}$ Universidad Autónoma de Nuevo León, Facultad de Ingeniería Mecánica y Eléctrica, Av. Pedro de Alba s/n, Ciudad \\ Universitaria C.P. 66450, San Nicolás de los Garza Nuevo León, México, \\ ${ }^{2}$ CIIDIT-Universidad Autónoma de Nuevo León, Km 10 de la nueva carretera al Aeropuerto Internacional de Monterrey PIIT \\ Monterrey, C.P. 66600, Apodaca, Nuevo León, México. \\ e-mail: saidagarcia@yahoo.com
}

\begin{abstract}
Undoped and tin $(\mathrm{Sn})$ doped zinc oxide $(\mathrm{ZnO})$ thin film have been deposited by spray pyrolysis method of zinc acetate and tin chloride. The concentration ratio of $[\mathrm{Sn}] /[\mathrm{Zn}]$ was varied from $0-5$ at \%. The effect of doping Sn on physical and optical properties was studied by different techniques such as X-ray diffraction for structural characterization, SEM for thickness and morphology, UV-Vis spectroscopy for optical properties, Hall effect and photoconductivity for electrical characterization. X-ray diffraction (XRD) patterns show that the films deposited are polycrystalline with (002) plane as the preferential orientation. According to Scherrer's equation, grain size values on the films are found between $30-45 \mathrm{~nm}$ with spherical shape. Optical transmittance was about $92 \%$ in visible range for the optimum film and shows that the band gap decreases from 3.29 to $3.17 \mathrm{eV}$.
\end{abstract}

\section{Introduction}

Zinc oxide is a transparent conducting oxide (TCO), a promising material for many different applications such as solar cells, gas sensors, ultrasonic oscillators and transducers [1], an inexpensive n-type semiconductor with a band gap of $3.3 \mathrm{eV}$ which has a hexagonal wurtzite structure [2] and furthermore, it is a piezoelectric material. It founds its applications in surface acoustic wave devices [3]. Due to its high optical transparency in the visible region and its electrical conductivity, $\mathrm{ZnO}$ thin films have been used as window layers and anti reflecting coating in solar cells [4]. Also it can be used in gas sensors [5]. ZnO thin films have been deposited by many techniques such as sputtering [6], chemical vapor deposition [7], sol-gel [8], laser ablation [9], and spray pyrolysis [10]. The last technique has been used, because of its simplicity, reproducibility, lack of toxicity and cost effectiveness. Moreover, incorporation of dopants is easier by this technique. Several doping elements for $\mathrm{ZnO}$ have been studied [11], and tin has shown to be a potential agent doping to enhance the physical properties of ZnO films. Prasada et al studied the effect of ethanol as solvent on thin films and showed to have an important effect on thickness and sheet resistivity [12].

In present work $\mathrm{Sn}$ doped and undoped $\mathrm{ZnO}$ thin films were prepared by the spray pyrolysis method on glass substrate, the structural, optical and electrical properties of $\mathrm{ZnO}$ thin films was studied.

\section{Experiment}

$\mathrm{ZnO}$ thin films were deposited on glass substrates by spray pyrolysis method. The precursor materials used was zinc acetate dihydrated $\left(\mathrm{Zn}\left(\mathrm{C}_{2} \mathrm{H}_{3} \mathrm{O}_{2}\right)_{2} \cdot 2 \mathrm{H}_{2} \mathrm{O}\right)$, prepared a stock solution and was $1 \mathrm{M}$ zinc acetate dehydrated, prepared by dissolving deionized water. The concentration of zinc acetate was 0.05 to $0.1 \mathrm{M}$ and the $\mathrm{Sn} / \mathrm{Zn}$ ratio in the solution was 5 at \% in the starting solution. The precursor solutions were prepared by 10,16 and $20 \mathrm{~mL}$ of $1 \mathrm{M}$ $\mathrm{Zn}\left(\mathrm{C}_{2} \mathrm{H}_{3} \mathrm{O}_{2}\right)_{2}$ and $0.062,0.098$ and $0.124 \mathrm{~g} \mathrm{SnCl}_{2}$ and dissolved in ethanol at $200 \mathrm{~mL}$. A few drops of acetic acid were added to aqueous solutions to prevent the formation of hydroxides. The nozzle was kept at a distance of $47 \mathrm{~cm}$ from the substrate during deposition. Air was used as the carrier gas, at the pressure of 65 psi. The deposition temperature was kept at $400^{\circ} \mathrm{C}$. Thin films were then annealed in a vacuum at $300^{\circ} \mathrm{C}$ during $1 \mathrm{~h}$.

When aerosol droplets come close to the substrates, a pyrolytic process occurs and $\mathrm{ZnO}$ films are produced. The possible reaction proposed by Paraguay et al. [13] is as follows:

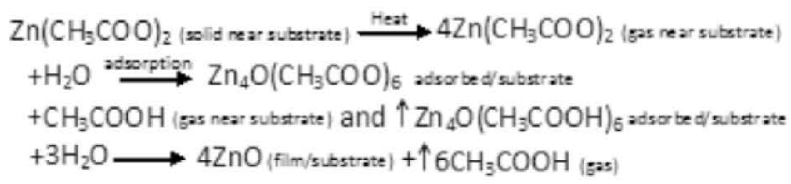


The thickness of the films was measured by Perfilometer. The film thicknesses were found as $\sim 150 \mathrm{~nm}$. The structural analysis of all the thin films was performed with a X-ray diffractometer with $\mathrm{Cu} \mathrm{K} \alpha\left(\lambda=1.54059 \mathrm{~A}^{\circ}\right)$ radiation. The diffractometer reflections were taken at room temperature and the value of $2 \theta$ were swapped between $20^{\circ}$ and $60^{\circ}$. The UV-Vis spectra of the films were recorded from $300 \mathrm{~nm}$ to $900 \mathrm{~nm}$ wavelength using Perkin Elmer Lamda 35 UV-Vis spectrophotometer at room temperature. Surface morphology and microstructure of each film were observed using a field-emission scanning electron microscope (FE-SEM). Electrical measurement was carried out by four probe method using Keithley Electrometer.

\section{Results and discussion}

$\mathrm{X}$-ray diffraction patterns of undoped $\mathrm{ZnO}$ and $\mathrm{Sn}$-doped $\mathrm{ZnO}$ films annealed in a vacuum at $300^{\circ} \mathrm{C}$ during $1 \mathrm{~h}$ are presented in figure 1 . These patterns show the peak of crystallized $\mathrm{ZnO},\left(\begin{array}{ll}0 & 0\end{array}\right)$ preferred orientation, confirming the polycrystalline films with a hexagonal wurtzite structure (Zincite, JCPDS 36-1451).
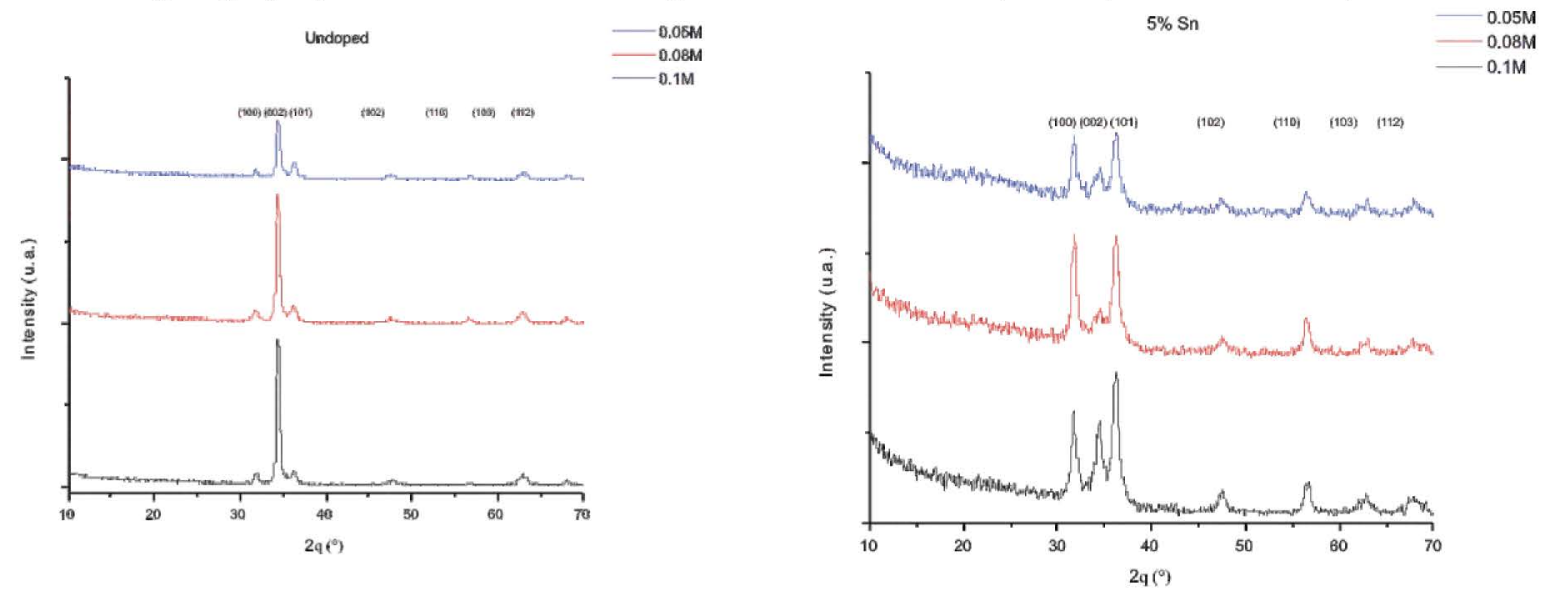

Figure 1. X-ray diffraction pattern of $\mathrm{ZnO}$ films undoped and $\mathrm{Sn}$ doped deposited on glass substrate has an enhanced $\left(\begin{array}{lll}0 & 0 & 2\end{array}\right)$ orientation.

These diffractographs show that the intensities of diffraction peaks declined as $\mathrm{ZnO}$ concentrations decreased, Sn doping within $\mathrm{ZnO}$ films also caused the crystallinity to detract.

The crystalline size of the deposited thin films is determined by using the Debye-Scherrer formula,

$$
D=\frac{0.94 \lambda}{B \cos \theta}
$$

where $\lambda$ is the $\mathrm{X}$-ray wavelength equal to $1.54 \AA, \theta$ is Bragg diffraction angle and $\mathrm{B}$ (radians) is the full-width at half-maximum. The average crystallite grain size is estimated to be $30 \mathrm{~nm}$ for undoped films and $45 \mathrm{~nm}$ for $\mathrm{Sn}$ doped films.

Optical transmission spectra of $\mathrm{Sn}$ doped and undoped $\mathrm{ZnO}$ thin films deposited on glass substrates are recorded as a function of wavelength in the range of $300-900 \mathrm{~nm}$ and shown in figure 2 . In order to obtain the band gap, the absorption coefficient $(\alpha)$ is calculated from the transmission and reflection data using the following relation

$$
\alpha=\frac{1}{t} \ln \frac{(1-R)}{T}
$$

where $t$ is the film thickness, $\mathrm{R}$ is the reflectance and $\mathrm{T}$ is the transmittance.

For the direct transition, the optical band gap energy of $\mathrm{ZnO}$ film is determined using the equation:

$$
\alpha h v=A(h v-E g)^{1 / 2}
$$


where $\mathrm{h} v$ is the photon energy and Eg is the optical band gap and A is a constant.
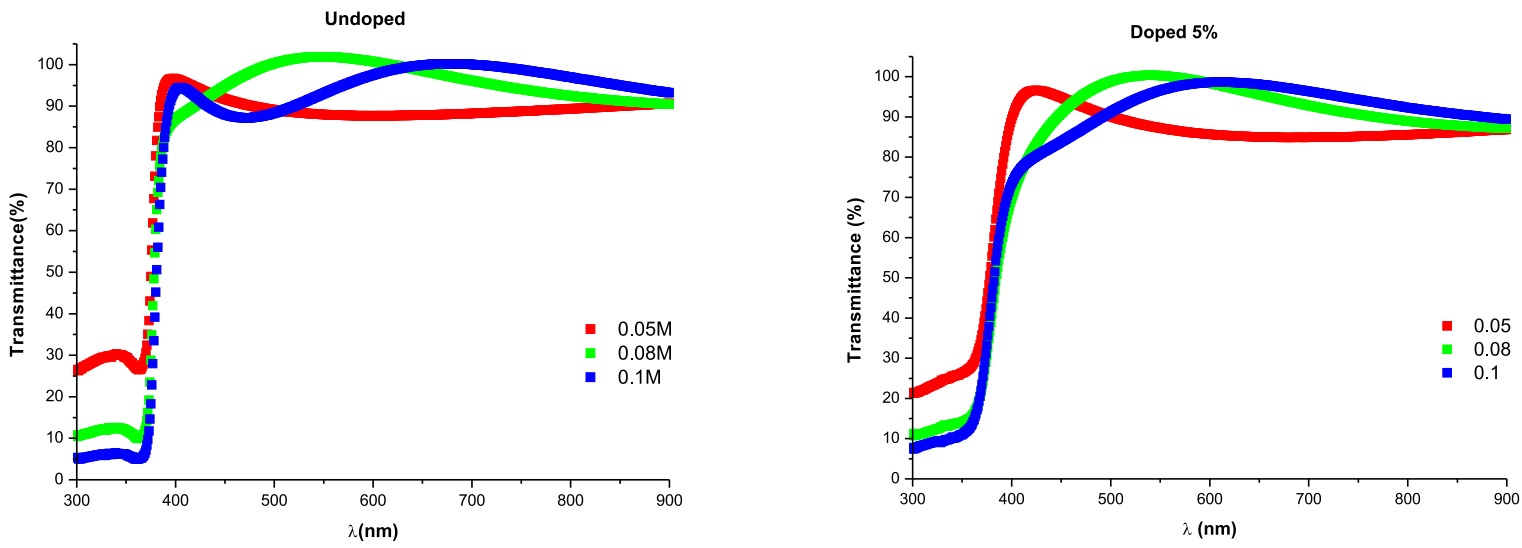

Figure 2. Transmittance spectra vs. wavelength for the $\mathrm{Sn}$ doped and undoped $\mathrm{ZnO}$ films. The average visible transmissions were about $92 \%$

Figure 3 shows the plot of $(\alpha h v)^{2}$ vs. hv for $\mathrm{ZnO}$ thin films. It has been observed that the plot of $(\alpha \mathrm{hv})^{2} \mathrm{vs.} \mathrm{h} v$ is linear over a wide range of photon energies, indicating a direct band to band transition. The intercepts (extrapolations) of these plots on the energy axis reflect the energy band gaps.
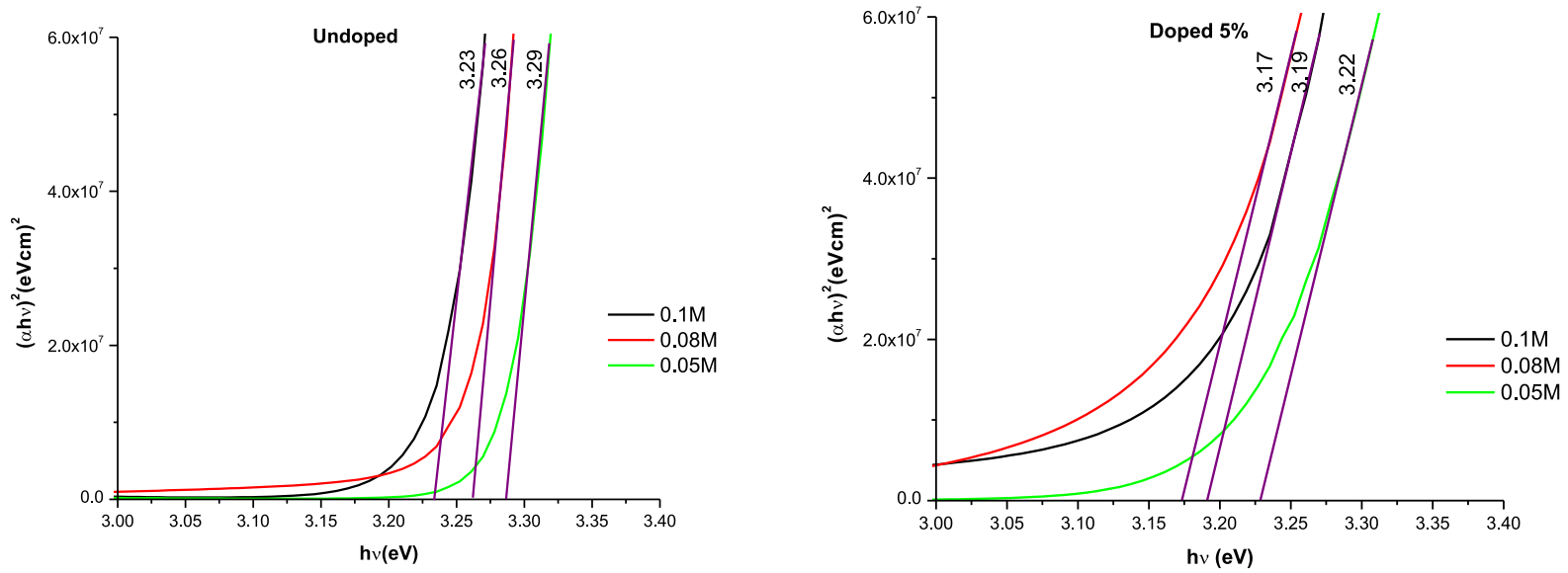

Figure 3. Tauc plot for the evaluation of band gap energy of $\mathrm{ZnO}$ doped and undoped thin films, respectively

The surface morphology of the undoped (a,c,e) and the Sn doped (b,d,f) ZnO thin films observed with SEM are shown in figure 4. Comparatively, tin doped films show the dense and less porous structure than undoped films.

Resistivity at room temperature measured on $\mathrm{Sn}$ doped and undoped $\mathrm{ZnO}$ films prepared at different doping ratio is given in figure 5, curve behavior showed a reduction in the resistivity value in $0.05 \mathrm{M}$ undoped to doped $5 \%$ at by five orders of magnitude $\left(10^{2} \Omega \mathrm{cm}\right.$ to $\left.10^{-2} \Omega \mathrm{cm}\right)$. The decrease in the resistivity of the films by $\mathrm{Sn}$ doping can be explained by the substitution of $\mathrm{Sn}^{4+}$ ions at the $\mathrm{Zn}^{2+}$ sites leading two free carriers. As the doping levels hcreased, more dopant atoms occupy the zinc lattices sites, which results in more charge carriers.

Electrical Hall-effect measurements were performed in order to investigate the electrical properties of the $\mathrm{ZnO}$ thin films, electron concentration and mobility are $6.609 \times 10^{19} \mathrm{~cm}^{-3}$ and 2.025 respectively. 

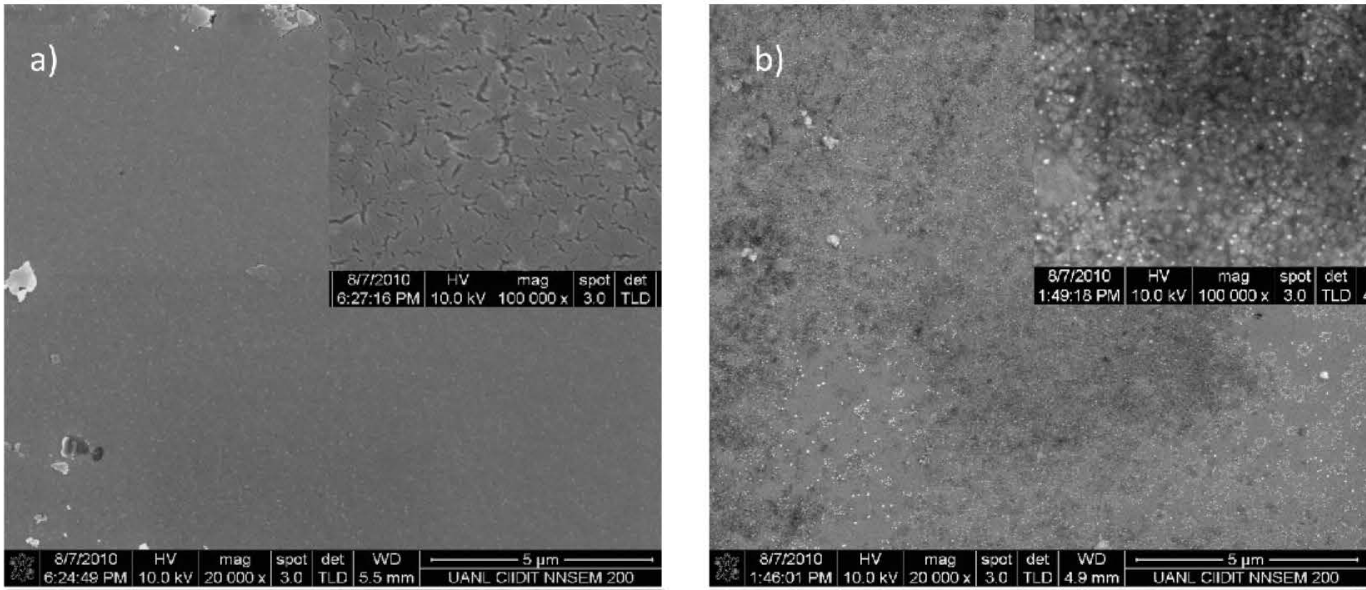

c)
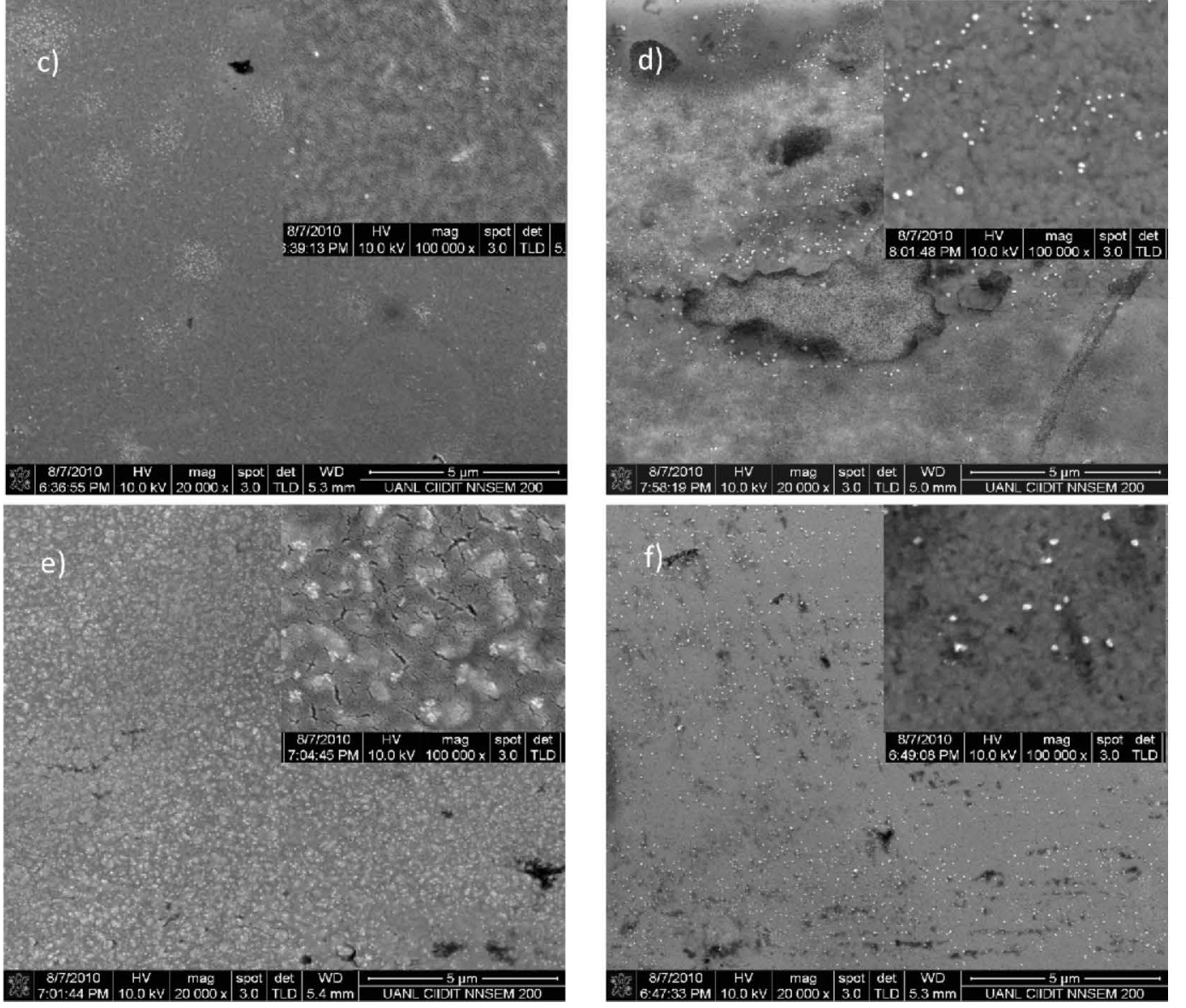

Figure 4. SEM microphotographs of Sn-doped $\mathrm{ZnO}$ thin films prepared with different $[\mathrm{Sn}] /[\mathrm{Zn}]$ ratios: (a, c, e) 0 and (b, d, f) $5 \%$, with $0.05(\mathrm{a}, \mathrm{b}), 0.08(\mathrm{c}, \mathrm{d})$ y $0.1 \mathrm{M}(\mathrm{e}, \mathrm{f})$. 


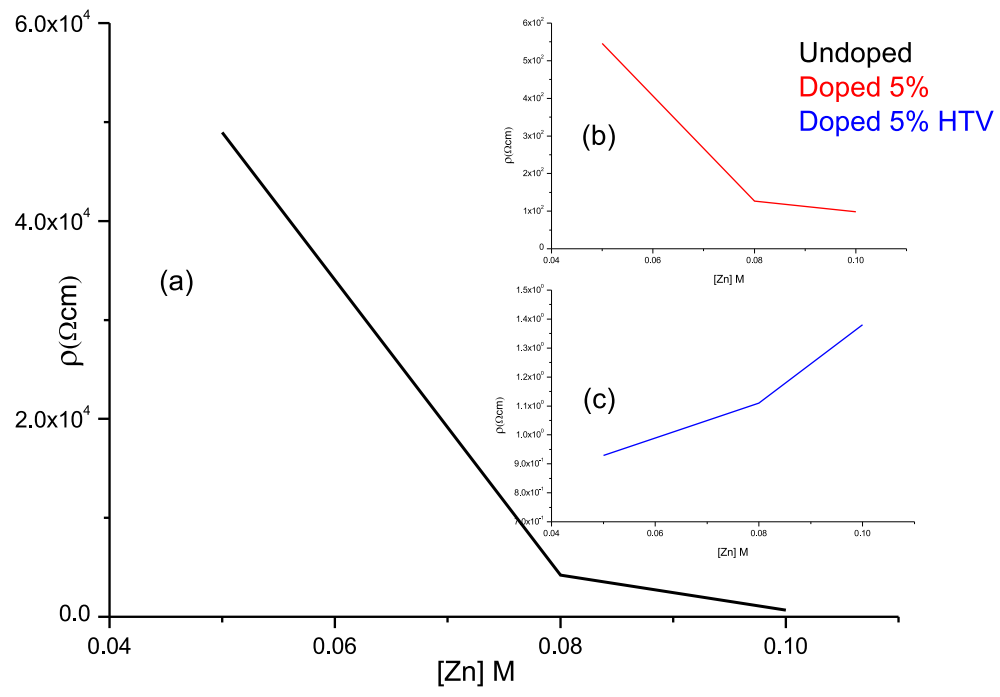

Figure 5. Variation of electrical resistivity of $\mathrm{ZnO}$ (a) undoped, (b) Sn doped and (c) Sn doped with heat treatment vacuum.

\section{Conclusions}

Sn doped and undoped $\mathrm{ZnO}$ thin films were prepared on glass substrates by spray pyrolysis. The doping concentration of 5 at $\%$ is proved to be optimum for tin doped zinc oxide thin films. According to X-rays diffraction, the $\mathrm{ZnO}$ films grow preferentially in the direction (002). The average grains size is about $37.5 \mathrm{~nm}$. The electrical resistivity decreases with level doping after heat treatment in a vacuum. The electron concentration is equal to $6.609 \times 10^{19} \mathrm{~cm}^{-3}$. Heat treatment in a vacuum improves significantly the resistivity, as well as optical and structural properties of Sn doped $\mathrm{ZnO}$ films. Small electron mobility can be attributed to the electrons trapped at grain boundaries of crystallites form potential barriers which reduces the mobility.

\section{Acknowledgements}

The authors are thankful to Dr.Roberto Carlos Ambrosio Lázaro, DEC, UACJ, Chihuahua, México for providing characterization facilities, CONACyT, PAICYT-UANL, PROMEP for the financial assistance.

\section{References}

[1] Malle Krunks, Enn Mellikov, J. Thin Solid Films 270 (1995) 33-36.

[2] U. Ozgur, Ya.I. Alikov, C. Liu, A. Teke, M.A. Reshchikov, S. Dogan, V. Avrutin, S.J. Cho, H. Morko, J. Appl. Phys. 98 (04130) (2005) 1-98.

[3] V.A. Karpina, V.L. Lazorenko, C.V. Lashkarev, V.D. Dobrowski, K.L. Kopylova, V.A. Baturin, S.A. Pustovoytov, A.Ju. Karpenko, Cryst. Res. Technol. 39 (2004) 980-992.

[4] S. Major, A. Banerjee, K.L. Chopra, Thin Solid Films 125 (1985) 179-185.

[5] F. Paraguay, M. Miki-Yoshida, J. Morales, J. Solis, W. Estrada, Superficies y Vacio 9 (1999) 245-247.

[6] C.A.O. Yongee, Lei Miao, Sakae Tanemura, Masaki Tanemura, Yohei Kuno, Yasuhiko Hahashi, Yukimasa Mori, Jpn. J. Appl. Phys. 45 (2006) 1623-1628.

[7] T.A. Polley, W.B. Carter, D.B. Poker, Thin Solid Films 357 (1999) 132-136.

[8] B. Kotlyarchuk, V. Savnuck, M. Oszwaldowski, Cryst. Res. Technol. 40 (2005) 1118-1123.

[9] Susan Huang, Tatiana Kaydanova, Alex Miedaner, David S. Ginley, U.S. Dept.Energy J. Undergraduate Res. 4 (2004) $70-73$.

10] Mujdat Caglar, Yasemin Caglar, Saliha Ilican, Phys. Stat. Sol. 4 (3) (2007) 1337-1343.

11]F. Paraguay, D.J. Morales, W. Estrada, L.E. Andrade, M. Miki-Yoshida, Thin Solid Films 366 (2000) 16-27.

12] T. Prasada Rao, M.C. Santhoshkumar, J. Applied Surface Science 255 (2009) 7212-7215.

[13] D.F. Paraguay, L.W. Estrada, D.R. Acosta, M.E. Andrade, Miki Yoshida, Thin Solid Films 350 (1999) 192. 